\title{
Nuclear Magnetic Resonance Studies of Reorientational Motion and Li Diffusion in $\mathrm{LiBH}_{4}-$ Lil Solid Solutions
}

\author{
Alexander V. Skripov, ${ }^{* \dagger}$ Alexei V. Soloninin, ${ }^{\dagger}$ Line H. Rude, ${ }^{\ddagger}$ Torben R. Jensen, ${ }^{\ddagger}$ and Yaroslav Filinchuk ${ }^{\S}$ \\ ${ }^{\dagger}$ Institute of Metal Physics, Ural Division of the Russian Academy of Sciences, S. Kovalevskoi 18, Ekaterinburg 620990, Russia \\ ${ }^{\ddagger}$ Center for Materials Crystallography, Interdisciplinary Nanoscience Center and Department of Chemistry, Aarhus University, \\ Langelandsgade 140, 8000 Aarhus C, Denmark \\ ${ }^{\S}$ Institute of Condensed Matter and Nanosciences, Université Catolique de Louvain, Place L. Pasteur 1, 1348 Louvain-la-Neuve, \\ Belgium
}

Supporting Information

ABSTRACT: To study the reorientational motion of the $\mathrm{BH}_{4}$ groups and the translational diffusion of $\mathrm{Li}^{+}$ions in $\mathrm{LiBH}_{4}-\mathrm{LiI}$ solid solutions with 2:1, 1:1, and 1:2 molar ratios, we have measured the ${ }^{1} \mathrm{H},{ }^{11} \mathrm{~B}$, and ${ }^{7} \mathrm{Li}$ NMR spectra and spin-lattice relaxation rates in these compounds over the temperature range $18-520 \mathrm{~K}$. It is found that, at low temperatures, the reorientational motion of the $\mathrm{BH}_{4}$ groups in $\mathrm{LiBH}_{4}-\mathrm{LiI}$ solid solutions is considerably faster than in all other borohydridebased systems studied so far. Our results are consistent with a coexistence of at least two types of reorientational processes with different characteristic rates. For the faster reorientational process, the average activation energies derived from our data are $53 \pm 4,39 \pm 4$, and $33 \pm 4 \mathrm{meV}$ for the $\mathrm{LiBH}_{4}-\mathrm{LiI}$ solid solutions with 2:1, 1:1, and 1:2 molar ratios, respectively. In the studied range of iodine concentrations, the $\mathrm{Li}^{+}$jump rates are found to decrease with increasing $\mathrm{I}^{-}$content. The activation energies for $\mathrm{Li}$ diffusion obtained from our data are $0.63 \pm 0.01,0.65 \pm 0.01$, and $0.68 \pm 0.01 \mathrm{eV}$ for the samples with $2: 1,1: 1$, and 1:2 molar ratios, respectively.

\section{INTRODUCTION}

Lithium borohydride, $\mathrm{LiBH}_{4}$, containing 18.4 mass \% of hydrogen is considered as a promising material for hydrogen storage $^{1}$ and a prospective superionic conductor. ${ }^{2}$ This compound is an ionic crystal consisting of $\mathrm{Li}^{+}$cations and tetrahedral $\left[\mathrm{BH}_{4}\right]^{-}$anions. At low temperatures $\mathrm{LiBH}_{4}$ has the orthorhombic structure (space group Pnma). ${ }^{3-5}$ At $T_{0} \approx 380 \mathrm{~K}$ it undergoes a first-order phase transition to the hexagonal structure (space group $\mathrm{Pb}_{3} m c$ ). ${ }^{3-5}$ The transition from the lowtemperature (LT) orthorhombic to the high-temperature (HT) hexagonal phase is accompanied by the 3 orders of magnitude increase in the electrical conductivity, ${ }^{2}$ so that the HT phase of $\mathrm{LiBH}_{4}$ can be considered as a lithium superionic conductor. The HT phase of $\mathrm{LiBH}_{4}$ is also characterized by the fast reorientational motion of $\mathrm{BH}_{4}$ tetrahedra ${ }^{6,7}$ with the jump rates exceeding $10^{12} \mathrm{~s}^{-1}$.

Recently, it has been found ${ }^{8-11}$ that the HT phase of $\mathrm{LiBH}_{4}$ can be stabilized down to low temperatures by a partial halide ion substitution of $\left[\mathrm{BH}_{4}\right]^{-}$anions. Such a substitution results in the formation of $\mathrm{Li}\left(\mathrm{BH}_{4}\right)_{1-y} \mathrm{X}_{y}$ solid solutions $(\mathrm{X}=\mathrm{Cl}, \mathrm{Br}$, or $\mathrm{I})$ with the hexagonal structure. The stabilizing effect increases with increasing size of the halide ion; thus, the strongest effect is observed for $\mathrm{I}^{-}$substitution. The temperature of the hexagonal-to-orthorhombic phase transition for $\mathrm{Li}\left(\mathrm{BH}_{4}\right)_{1-y} \mathrm{I}_{y}$ solid solutions is found to decrease with increasing iodine
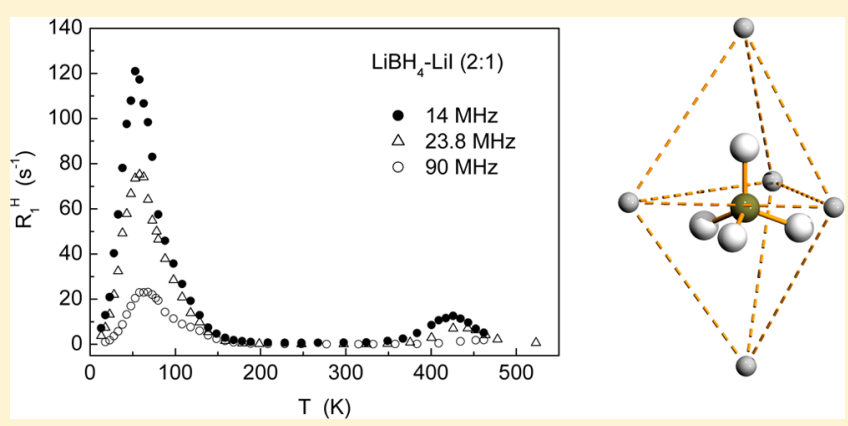

content, from $351 \mathrm{~K}$ for $y=0.067$ to $213 \mathrm{~K}$ for $y=0.25 .^{12}$ For $y$ $=0.33$, no signs of the phase transition have been found down to $173 \mathrm{~K}^{12}$ Thus, the hexagonal $\mathrm{Li}\left(\mathrm{BH}_{4}\right)_{1-y} \mathrm{I}_{y}$ solid solutions with $y \geq 0.33$ appear to be stable down to low temperatures. In practice, these solid solutions are prepared by ball milling the $\mathrm{LiBH}_{4}-\mathrm{LiI}$ mixtures with subsequent annealing. It is interesting to note that while the room-temperature phase of lithium iodide, $\alpha$-LiI, has a cubic NaCl-type structure, the lowtemperature $(\beta)$ modification of $\mathrm{LiI}$ is hexagonal (space group $\mathrm{P}_{3} m c$ ). Thus, the HT phase of $\mathrm{LiBH}_{4}$ and $\beta$-LiI have similar structures. Using the stabilizing effect of $\mathrm{I}^{-}$substitution, it is possible to obtain compounds with rather high $\mathrm{Li}$ ion mobility at room temperature.

Experimental studies of the relations between the crystal structure, $\mathrm{BH}_{4}$ rotational dynamics and $\mathrm{Li}$ ion mobility are expected to contribute to the search for new materials with high ionic conductivity. Microscopic information on atomic motion in borohydrides can be obtained from nuclear magnetic resonance $(\mathrm{NMR})^{2,13-24}$ and quasielastic neutron scattering (QENS) 6,7,25-28 measurements. The results of the first NMR measurements of the ${ }^{7} \mathrm{Li}$ spin-lattice relaxation rates in

Received: August 14, 2012

Revised: November 22, 2012

Published: November 28, 2012 
$\mathrm{LiBH}_{4}-\mathrm{LiI}$ solid solutions with 7:1 and 3:1 molar ratios ${ }^{8}$ suggested an increase in $\mathrm{Li}$ ion mobility due to the iodine doping. Recent QENS studies of $\mathrm{BH}_{4}$ reorientations in $\mathrm{LiBH}_{4}-$ LiI systems with 4:1, 2:1, and 1:1 molar ratios ${ }^{29}$ have revealed that the reorientation jump rate $\tau^{-1}$ increases, and the corresponding activation energy decreases with increasing iodine content. However, the range of changes in $\tau^{-1}$ observed by QENS experiments ${ }^{29}$ is less than 1 order of magnitude. NMR measurements of nuclear spin-lattice relaxation rates can, in principle, trace the changes in $\tau^{-1}$ over much broader dynamic ranges. For example, the $\mathrm{BH}_{4}$ reorientation rates in $\mathrm{NaBH}_{4}$ and $\mathrm{KBH}_{4}$ were probed over the range of $10^{4}-10^{12} \mathrm{~s}^{-1}$ ( 8 orders of magnitude) by the ${ }^{1} \mathrm{H}$ and ${ }^{11} \mathrm{~B}$ spin-lattice relaxation measurements. ${ }^{18}$ Another advantage of NMR is that the spin-lattice relaxation measurements at different resonance frequencies allow one to detect the presence of a distribution of atomic jump rates. ${ }^{30}$ Such a distribution is expected to exist in $\mathrm{LiBH}_{4}-\mathrm{LiI}$ solid solutions where the local environment changes from one $\mathrm{BH}_{4}$ group to another. The aim of the present work is to investigate both the reorientational motion of $\mathrm{BH}_{4}$ groups and $\mathrm{Li}$ diffusion in $\mathrm{LiBH}_{4}-\mathrm{LiI}$ solid solutions with $2: 1,1: 1$, and 1:2 molar ratios using ${ }^{1} \mathrm{H},{ }^{11} \mathrm{~B}$, and ${ }^{7} \mathrm{Li}$ NMR measurements of the spectra and spin-lattice relaxation rates over wide ranges of temperature $(18-520 \mathrm{~K})$ and resonance frequency (14-90 $\mathrm{MHz})$.

\section{EXPERIMENTAL METHODS}

The sample preparation was analogous to that described in ref 11. The mixtures of lithium borohydride $\mathrm{LiBH}_{4}$ (95\%, Aldrich) and lithium iodide LiI (99.99\%, Aldrich) corresponding to 2:1, 1:1, and 1:2 molar ratios were ball-milled in a Fritch Pulverisette 4 in an argon atmosphere using tungsten carbide (WC) balls and vial with 1:40 sample to balls mass ratio. To minimize the sample heating, a 2 min milling period was followed by a $2 \mathrm{~min}$ pause, and this procedure was repeated 60 times. The ball-milled samples were transferred to corundum crucibles, placed in argon-filled quartz tubes, sealed, and annealed at $280{ }^{\circ} \mathrm{C}$ for $12-17 \mathrm{~h}$. As shown in ref 11 , such a procedure yields hexagonal single-phase solid solutions Li$\left(\mathrm{BH}_{4}\right)_{1-y} \mathrm{I}_{y}$. The samples were characterized using X-ray diffraction and FT-IR spectra. Powder X-ray diffraction data were collected at room temperature on the sample with 2:1 molar ratio using SuperNova diffractometer from Oxford Diffraction equipped with a microfocus Mo K $\alpha(0.71073 \AA)$ X-ray source and Atlas CCD detector placed $60 \mathrm{~mm}$ from the sample. Data were collected with an exposure time of $\sim 180 \mathrm{~s}$. The sample was mounted in a $0.5 \mathrm{~mm}$ glass capillary sealed with glue. FT-IR spectra were recorded using Bruker ALPHA FT-IR spectrometer. The spectra were obtained in the 4000$350 \mathrm{~cm}^{-1}$ range with the resolution of $2 \mathrm{~cm}^{-1}$. Ten scans were collected and averaged for the background and for each of the samples. The measurements were conducted in air; however, the water absorption was limited due to the short exposure time of $\sim 10 \mathrm{~s}$. The results of the structural and FT-IR analysis are shown in the Supporting Information. For NMR experiments, all the samples were sealed in glass tubes under $\sim 500$ mbar of nitrogen gas. The sample with 2:1 molar ratio was additionally examined by X-ray powder diffraction inside the NMR tube, using MAR345 diffractometer and Mo $\mathrm{K} \alpha$ rotating anode generator. The single-phase quality of the sample was confirmed, the unit cell parameters being very close to those obtained on the sample in $0.5 \mathrm{~mm}$ glass capillary.
In order to verify the stability of the hexagonal solid solution phase down to low temperatures, additional X-ray diffraction measurements at room temperature and at $T=80 \mathrm{~K}$ were performed for all the studied samples about 9 months after the NMR experiments. These diffraction measurements have confirmed the stability of the hexagonal phase in our $2: 1,1: 1$, and $1: 2 \mathrm{LiBH}_{4}-\mathrm{LiI}$ samples down to $80 \mathrm{~K}$, in the sense that there are no signs of the hexagonal-to-orthorhombic phase transition. For all the samples, the lattice parameters of the hexagonal phase at room temperature and at $80 \mathrm{~K}$ are shown in Table S1 of the Supporting Information. For the 2:1 sample, the single hexagonal phase was observed both at room temperature and at $80 \mathrm{~K}$. For the $1: 1$ and 1:2 samples, the hexagonal phase coexisted with a small amount of the cubic LiI phase both at room temperature and at $80 \mathrm{~K}$. It should be noted that the refined $\mathrm{BH}_{4} / \mathrm{I}$ content in the hexagonal phase did not change with temperature, and the cell parameters changed (see Table S1) by values typical of thermal expansion; ${ }^{5}$ therefore, we can conclude that there was no phase segregation on cooling. Most probably, the appearance of the minor LiI phase in the samples with high iodine content results from a very slow segregation process (on the time scale of months). Similar slow segregation of $\mathrm{LiCl}$ was reported for $\mathrm{LiBH}_{4}-\mathrm{LiCl}$ solid solutions. ${ }^{\text {I0 }}$

NMR measurements were performed on a pulse spectrometer with quadrature phase detection at the frequencies $\omega / 2 \pi=$ 14, 23.8, and $90 \mathrm{MHz}$ for ${ }^{1} \mathrm{H}$ and $28 \mathrm{MHz}$ for both ${ }^{11} \mathrm{~B}$ and ${ }^{7} \mathrm{Li}$. The magnetic field was provided by a $2.1 \mathrm{~T}$ iron-core Bruker magnet. A home-built multinuclear continuous-wave NMR magnetometer working in the range $0.32-2.15 \mathrm{~T}$ was used for field stabilization. For rf pulse generation, we used a home-built computer-controlled pulse programmer, the PTS frequency synthesizer (Programmed Test Sources, Inc.), and a $1 \mathrm{~kW}$ Kalmus wideband pulse amplifier. Typical values of the $\pi / 2$ pulse length were $2-3 \mu \mathrm{s}$ for all nuclei studied. For the measurements at $T \leq 470 \mathrm{~K}$, a probehead with the sample was placed into an Oxford Instruments CF1200 continuous-flow cryostat using helium or nitrogen as a cooling agent. The sample temperature, monitored by a chromel- $(\mathrm{Au}-\mathrm{Fe})$ thermocouple, was stable to $\pm 0.1 \mathrm{~K}$. Measurements in the temperature range $470-520 \mathrm{~K}$ were performed using a furnace probehead; for this setup, the sample temperature, monitored by a copper-constantan thermocouple, was stable to $\pm 0.5 \mathrm{~K}$. The nuclear spin-lattice relaxation rates were measured using the saturation-recovery method. NMR spectra were recorded by Fourier transforming the solid echo signals (pulse sequence $\left.\pi / 2_{x}-t-\pi / 2_{y}\right)$.

\section{RESULTS AND DISCUSSION}

Overview. For all the studied $\mathrm{LiBH}_{4}-\mathrm{LiI}$ solid solutions, the measured temperature dependences of the proton spinlattice relaxation rate $R_{1}^{\mathrm{H}}$ exhibit two peaks. As an example of the data, Figure 1 shows the behavior of the proton spin-lattice relaxation rates measured at three resonance frequencies for the 2:1 sample. It can be seen from this figure that both relaxation rate peaks are frequency-dependent, as typical of the relaxation mechanism due to the nuclear dipole-dipole interaction modulated by atomic motion. ${ }^{31}$ For this mechanism, the $R_{1}^{\mathrm{H}}(T)$ maximum is expected to occur at the temperature at which the atomic jump rate $\tau^{-1}$ becomes nearly equal to the resonance frequency $\omega$. The amplitude of this maximum is determined by the strength of the fluctuating part of the dipole-dipole interaction. Comparing the $R_{1}^{\mathrm{H}}(T)$ data for 


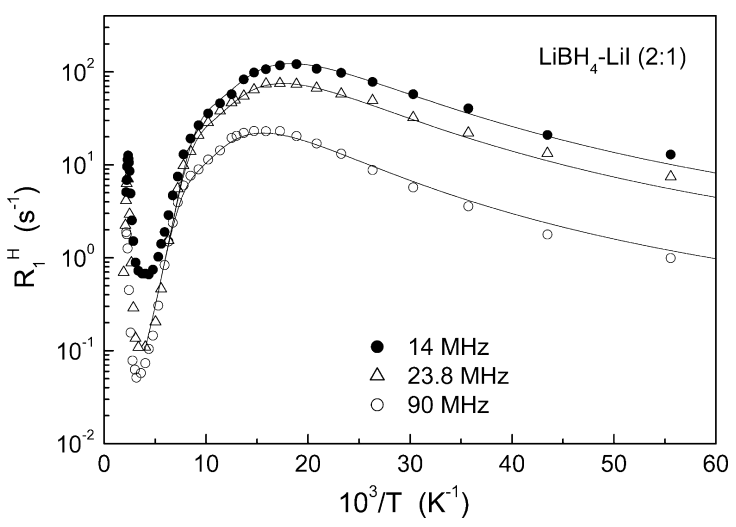

Figure 1. Proton spin-lattice relaxation rates measured at 14, 23.8, and $90 \mathrm{MHz}$ for $\mathrm{LiBH}_{4}-\mathrm{LiI}(2: 1)$ as functions of the inverse temperature. The solid lines show the simultaneous fits of the model with a two-peak distribution of the activation energies to the data in the range of the low-temperature $R_{1}^{\mathrm{H}}(T)$ peak.

$\mathrm{LiBH}_{4}-\mathrm{LiI}$ with those for pure $\mathrm{LiBH}_{4},{ }^{15-17}$ we can conclude that the main low-temperature relaxation rate peak originates from the reorientational motion of $\mathrm{BH}_{4}$ groups, while the minor high-temperature relaxation rate peak is due to the longrange diffusion of $\mathrm{Li}$ ions. It should be noted that for the HT phase of $\mathrm{LiBH}_{4}$ the reorientational motion cannot be probed by NMR, since at $T>T_{0}$ the jump rate of $\mathrm{BH}_{4}$ reorientations is too high to contribute substantially to $R_{1}^{\mathrm{H}}$, so that the behavior of $R_{1}^{\mathrm{H}}(T)$ in this temperature range is determined by the slower process of Li diffusion. ${ }^{15-17}$ The stabilization of the HT phase of $\mathrm{LiBH}_{4}$ by the iodine substitution allows us to probe the reorientational motion in the hexagonal phase over a wide temperature range. Our results show that, at low temperatures, the $\mathrm{BH}_{4}$ reorientations in $\mathrm{LiBH}_{4}-\mathrm{LiI}$ solid solutions are much faster than in all other borohydride-based systems studied so far. In fact, for the 2:1 sample, the $R_{1}^{\mathrm{H}}(T)$ maximum at $\omega / 2 \pi=$ $14 \mathrm{MHz}$ is observed near $55 \mathrm{~K}$; i.e., the reorientational jump rate $\tau^{-1}$ reaches the value of $\omega \sim 10^{8} \mathrm{~s}^{-1}$ already at this temperature. For the $1: 1$ and 1:2 samples, the $R_{1}^{\mathrm{H}}(T)$ maxima are observed at even lower temperatures (40 and $33 \mathrm{~K}$, respectively, at $\omega / 2 \pi=14 \mathrm{MHz}$ ); therefore, the reorientational motion in these samples is even faster than in the 2:1 sample. The behavior of the proton spin-lattice relaxation rates for different $\mathrm{LiBH}_{4}-\mathrm{LiI}$ solid solutions in the region of the lowtemperature peak is compared in Figure 2, showing the experimental results at $\omega / 2 \pi=23.8 \mathrm{MHz}$. For comparison, for the LT phase of $\mathrm{LiBH}_{4}$ the $R_{1}^{\mathrm{H}}(T)$ maximum due to the reorientational motion occurs near $158 \mathrm{~K}$ at the resonance frequency of $14 \mathrm{MHz}$ and near $164 \mathrm{~K}$ at $23.8 \mathrm{MHz}{ }^{15}$

According to the standard theory ${ }^{31}$ of nuclear spin-lattice relaxation due to atomic motion, in the limit of slow motion $(\omega \tau \gg 1), R_{1}^{\mathrm{H}}$ should be proportional to $\omega^{-2} \tau^{-1}$, and in the limit of fast motion $(\omega \tau \ll 1), R_{1}^{\mathrm{H}}$ should be proportional to $\tau$ being frequency-independent. If the temperature dependence of the jump rate $\tau^{-1}$ is governed by the Arrhenius law with the activation energy $E_{\mathrm{a}}$

$$
\tau^{-1}=\tau_{0}^{-1} \exp \left(-E_{\mathrm{a}} / k_{\mathrm{B}} T\right)
$$

a plot of $\ln R_{1}^{\mathrm{H}}$ vs $T^{-1}$ should be linear in the limits of both slow and fast motion with the slopes $-E_{\mathrm{a}} / k_{\mathrm{B}}$ and $E_{\mathrm{a}} / k_{\mathrm{B}}$, respectively. As can be seen from Figures 1 and 2, in the region of the lowtemperature peak, the observed high-temperature slope of the $\log R_{1}^{\mathrm{H}}$ vs $T^{-1}$ plot is considerably steeper than the low-

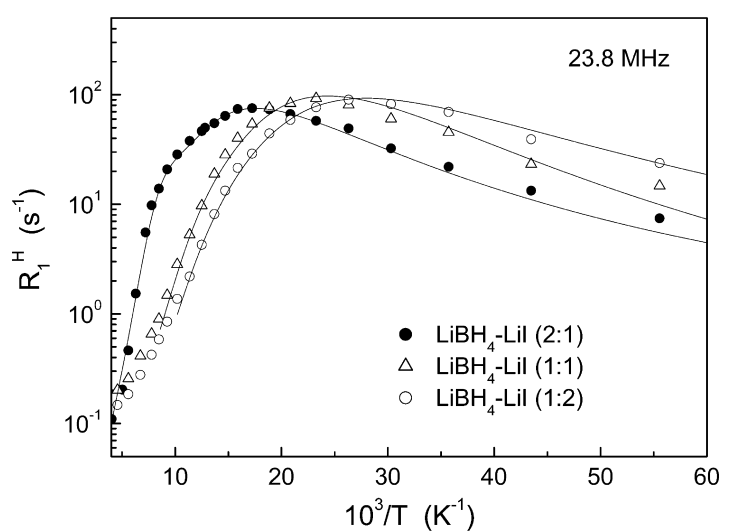

Figure 2. Proton spin-lattice relaxation rates measured at $23.8 \mathrm{MHz}$ for the solid solutions $\mathrm{LiBH}_{4}-\mathrm{LiI}(2: 1,1: 1$, and 1:2) as functions of the inverse temperature in the range of the low-temperature $R_{1}^{\mathrm{H}}(T)$ peak. For each of the samples, the solid line shows the simultaneous fit of the model with a two-peak distribution of the activation energies to the data.

temperature slope. Moreover, the experimental frequency dependence of $R_{1}^{\mathrm{H}}$ at the low-temperature slope is much weaker than the expected $\omega^{-2}$ dependence. These features are consistent with the presence of a broad distribution of $\mathrm{H}$ jump rates. ${ }^{30}$ Figure 2 shows that the increase in the iodine content leads to a shift of the peak position to lower temperatures; this means that the most probable values of the jump rate $\tau^{-1}$ increase with increasing $\mathrm{I}^{-}$concentration. Qualitatively, this result agrees with that obtained by $\mathrm{QENS}^{29}$ for the $\mathrm{LiBH}_{4}-\mathrm{LiI}$ solid solutions with $4: 1,2: 1$, and 1:1 molar ratios. Such a behavior may be related to the increase in the lattice parameters with increasing iodine content. ${ }^{11}$

Figure 3 shows the behavior of the proton spin-lattice relaxation rates measured at three resonance frequencies for the

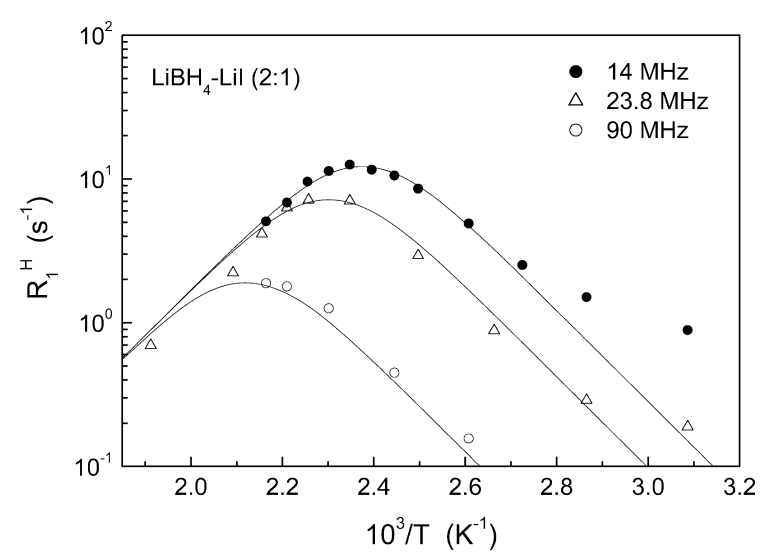

Figure 3. Proton spin-lattice relaxation rates measured at 14, 23.8, and $90 \mathrm{MHz}$ for $\mathrm{LiBH}_{4}-\mathrm{LiI}(2: 1)$ as functions of the inverse temperature in the range of the high-temperature $R_{1}^{\mathrm{H}}(T)$ peak. The solid lines show the simultaneous fits of the BPP model to the data.

2:1 sample in the region of the high-temperature peak. The behavior of the proton spin-lattice relaxation rates for different $\mathrm{LiBH}_{4}-\mathrm{LiI}$ solid solutions in the region of the high-temperature peak is compared in Figure 4, showing the experimental results at $\omega / 2 \pi=23.8 \mathrm{MHz}$. It should be noted that, for all the samples studied, the amplitude of the high-temperature $R_{1}^{\mathrm{H}}$ peak is much smaller than that of the low-temperature peak (cf. Figures 2 and 4 ). This feature supports the assignment of the 


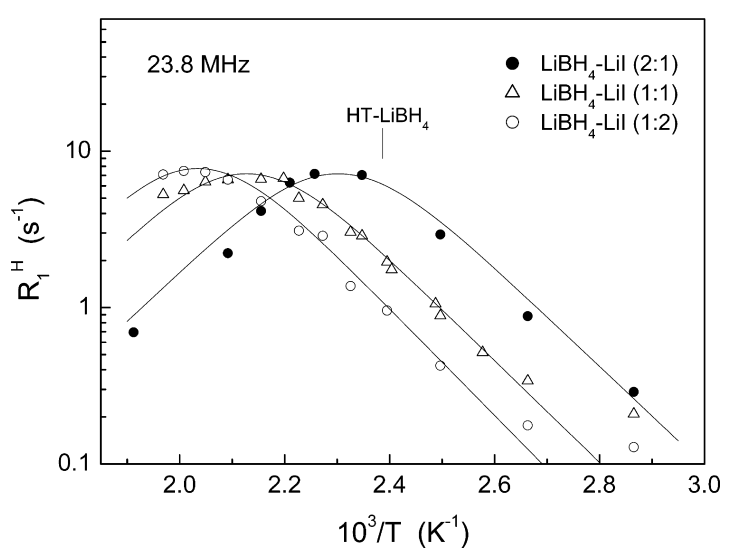

Figure 4. Proton spin-lattice relaxation rates measured at $23.8 \mathrm{MHz}$ for the solid solutions $\mathrm{LiBH}_{4}-\mathrm{LiI}(2: 1,1: 1$, and 1:2) as functions of the inverse temperature in the range of the high-temperature $R_{1}^{\mathrm{H}}(T)$ peak. For each of the samples, the solid line shows the simultaneous fit of the BPP model to the data. The vertical bar shows the position of the $R_{1}^{\mathrm{H}}(T)$ maximum for the $\mathrm{HT}$ phase of $\mathrm{LiBH}_{4}$ at $23.8 \mathrm{MHz}^{17}$

high-temperature $R_{1}^{\mathrm{H}}$ peak to the long-range $\mathrm{Li}$ diffusion. Indeed, the ${ }^{1} \mathrm{H}-{ }^{7} \mathrm{Li}$ dipole-dipole interaction (which is modulated by the jumps of $\mathrm{Li}$ ions) in $\mathrm{LiBH}_{4}-\mathrm{LiI}$ is an order of magnitude weaker than the ${ }^{1} \mathrm{H}-{ }^{1} \mathrm{H}$ and ${ }^{1} \mathrm{H}-{ }^{11} \mathrm{~B}$ dipoledipole interactions (which are modulated by the $\mathrm{BH}_{4}$ reorientations). ${ }^{15,17}$ This assignment is also supported by the ${ }^{7} \mathrm{Li}$ NMR results to be discussed below. As can be seen from Figure 4, the high-temperature $R_{1}^{\mathrm{H}}$ peak shifts to higher temperatures with the increase in the iodine content. Note that the position of the $R_{1}^{\mathrm{H}}$ peak due to Li diffusion in the HT phase of pure $\mathrm{LiBH}_{4}\left(419 \mathrm{~K}\right.$ at $\omega / 2 \pi=23.8 \mathrm{MHz},{ }^{17}$ shown by the vertical bar in Figure 4) is also consistent with this trend. These results indicate that the rate of Li diffusive jumps $\tau_{\mathrm{d}}{ }^{-1}$ decreases with increasing $\mathrm{I}^{-}$concentration.

The temperature dependences of the ${ }^{11} \mathrm{~B}$ spin-lattice relaxation rate $R_{1}^{\mathrm{B}}$ for the studied $\mathrm{LiBH}_{4}-\mathrm{LiI}$ solid solutions also exhibit two peaks. The $R_{1}^{\mathrm{B}}(T)$ peaks are observed at nearly the same temperatures as the corresponding ${ }^{1} \mathrm{H}$ spin-lattice relaxation rate peaks. As an example of the data, Figure 5 shows the behavior of the ${ }^{11} \mathrm{~B}$ spin-lattice relaxation rates measured at $\omega / 2 \pi=28 \mathrm{MHz}$ for the $2: 1$ and $1: 1$ samples. It is natural to

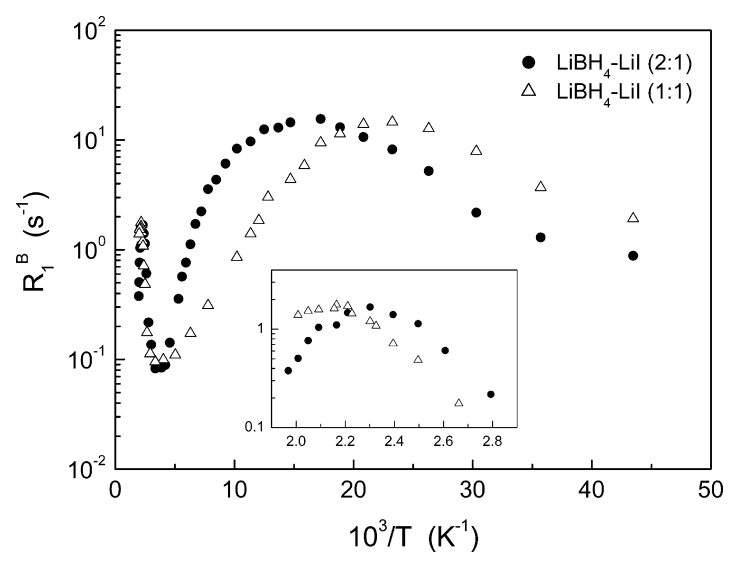

Figure 5. ${ }^{11} \mathrm{~B}$ spin-lattice relaxation rates measured at $28 \mathrm{MHz}$ for the solid solutions $\mathrm{LiBH}_{4}-\mathrm{LiI}(2: 1$ and $1: 1)$ as functions of the inverse temperature. The inset shows the expanded view of the data in the range of the high-temperature peak. attribute the low-temperature $R_{1}^{\mathrm{B}}$ peak to the reorientational motion of $\mathrm{BH}_{4}$ groups and the high-temperature one to the translational diffusion of $\mathrm{Li}$ ions. Previous NMR studies of atomic motion in borohydrides ${ }^{15,17-19,22}$ have shown that the analysis of the $R_{1}^{\mathrm{B}}(T)$ data gives essentially the same information on motional parameters as that of the $R_{1}^{\mathrm{H}}(T)$ data for the same compounds.

The temperature dependences of the ${ }^{7} \mathrm{Li}$ spin-lattice relaxation rates $R_{1}^{\mathrm{Li}}$ measured at $28 \mathrm{MHz}$ for all the studied

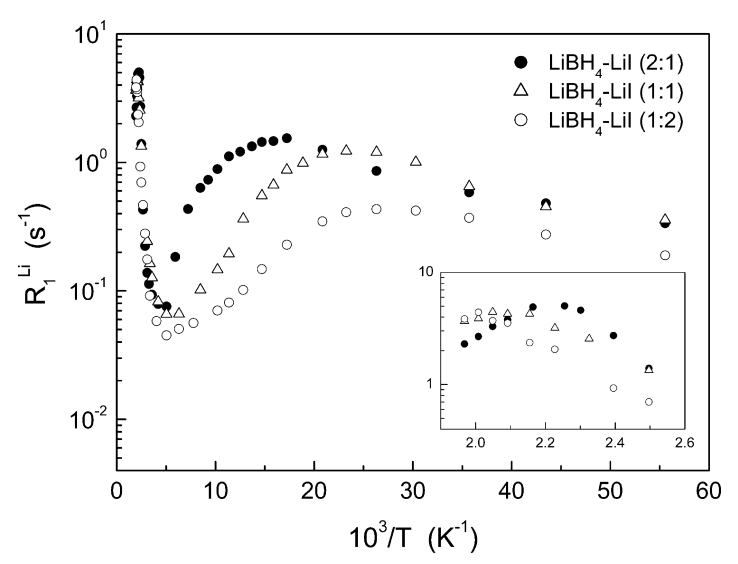

Figure 6. ${ }^{7} \mathrm{Li}$ spin-lattice relaxation rates measured at $28 \mathrm{MHz}$ for the solid solutions $\mathrm{LiBH}_{4}-\mathrm{LiI}(2: 1,1: 1$, and 1:2) as functions of the inverse temperature. The inset shows the expanded view of the data in the range of the high-temperature peak.

samples are shown in Figure 6. As in the cases of the ${ }^{1} \mathrm{H}$ and ${ }^{11} \mathrm{~B}$ spin-lattice relaxation, the temperature dependence of $R_{1}^{\mathrm{Li}}$ exhibits two peaks. However, in contrast to the cases of the ${ }^{1} \mathrm{H}$ and ${ }^{11} \mathrm{~B}$ relaxation, the amplitude of the low-temperature $R_{1}^{\mathrm{Li}}$ peak appears to be smaller than that of the high-temperature $R_{1}^{\mathrm{Li}}$ peak. This feature supports the assignment of the hightemperature peak to the long-range diffusion of $\mathrm{Li}$ ions. In fact, the reorientational motion of $\mathrm{BH}_{4}$ groups is expected to modulate only a small part of the ${ }^{7} \mathrm{Li}-{ }^{1} \mathrm{H}$ dipole-dipole interaction, while the long-range diffusion of $\mathrm{Li}$ ions should lead to a full modulation of the ${ }^{7} \mathrm{Li}-{ }^{1} \mathrm{H},{ }^{7} \mathrm{Li}-{ }^{11} \mathrm{~B},{ }^{7} \mathrm{Li}-{ }^{129} \mathrm{I}$, and ${ }^{7} \mathrm{Li}-{ }^{7} \mathrm{Li}$ dipole-dipole interactions. The assignment of the high-temperature peak to the diffusion of $\mathrm{Li}$ ions is also consistent with the observed behavior of the ${ }^{7} \mathrm{Li}$ NMR line width. Figure 7 shows the temperature dependences of the width (full width at half-maximum) of the ${ }^{7} \mathrm{Li}$ NMR lines for all the studied $\mathrm{LiBH}_{4}-\mathrm{LiI}$ solid solutions. The observed strong narrowing of the ${ }^{7} \mathrm{Li}$ NMR lines indicates the onset of the diffusive $\mathrm{Li}$ ion motion; a substantial narrowing is expected to occur at the temperature at which the jump rate $\tau_{\mathrm{d}}{ }^{-1}$ exceeds the line width for the "rigid" lattice ${ }^{31}\left(\sim 10^{4} \mathrm{~s}^{-1}\right)$. At the hightemperature plateau, the observed line width is determined by the magnetic field inhomogeneity over the sample volume; this means that the dipole-dipole interactions of ${ }^{7} \mathrm{Li}$ spins are fully averaged out by a fast diffusive motion of $\mathrm{Li}$ ions. However, as in the case of the HT phase of $\mathrm{LiBH}_{4}, 2,16,17$ the electric quadrupole interaction of ${ }^{7} \mathrm{Li}$ nuclei is not averaged out by the fast diffusive motion, so that the high-temperature ${ }^{7} \mathrm{Li}$ NMR spectra consist of a sharp central line and a pair of well-resolved quadrupole satellites. Figure 8 shows the ${ }^{7} \mathrm{Li}$ NMR spectra at $T$ $=470 \mathrm{~K}$ for the three $\mathrm{LiBH}_{4}-\mathrm{LiI}$ solid solutions and for the previously studied ${ }^{17} \mathrm{HT}$ phase of $\mathrm{LiBH}_{4}$. The value of the 


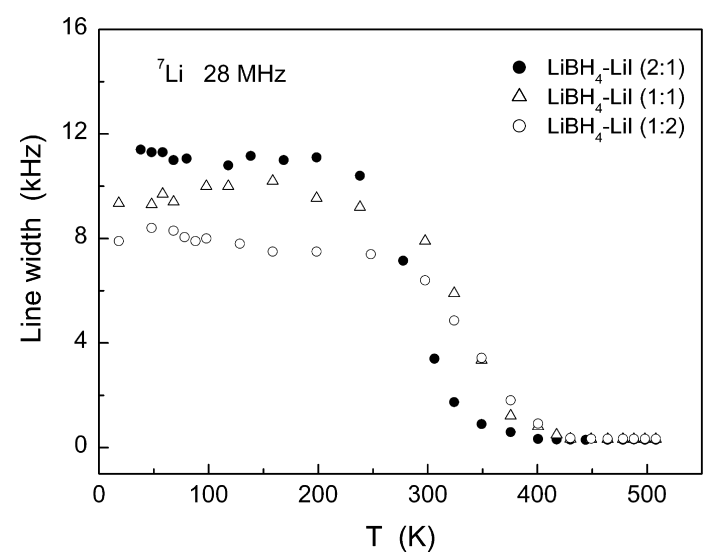

Figure 7. Temperature dependences of the width (full width at halfmaximum) of the central ${ }^{7} \mathrm{Li}$ NMR line measured at $28 \mathrm{MHz}$ for the solid solutions $\mathrm{LiBH}_{4}-\mathrm{LiI}(2: 1,1: 1$, and 1:2).

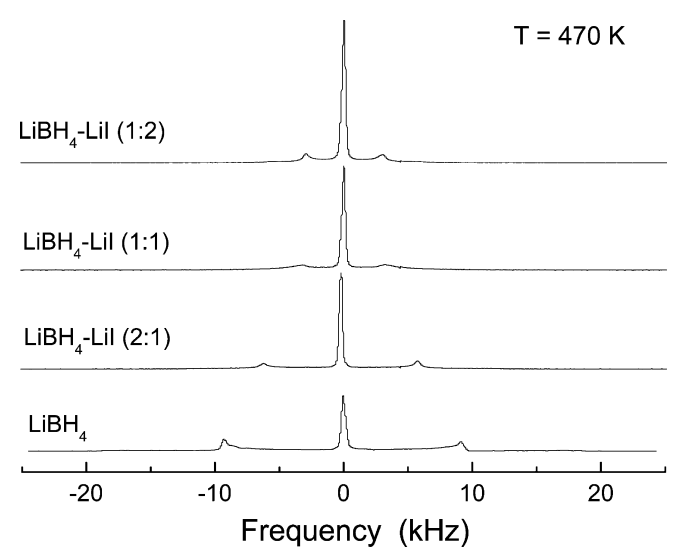

Figure 8. ${ }^{7} \mathrm{Li} \mathrm{NMR}$ spectra at $\mathrm{T}=470 \mathrm{~K}$ for $\mathrm{LiBH}_{4}$ (ref 17) and for the solid solutions $\mathrm{LiBH}_{4}-\mathrm{LiI}(2: 1,1: 1$, and 2:1).

quadrupole interaction parameter $\nu_{\mathrm{Q}}$ that determines the line splitting in the ${ }^{7} \mathrm{Li}$ NMR spectra is found to decrease with increasing iodine content, changing from $36.8 \mathrm{kHz}$ (HT phase of $\mathrm{LiBH}_{4}$ ) to $24.0 \mathrm{kHz}$ (2:1 sample), $12.8 \mathrm{kHz}$ (1:1 sample), and $11.8 \mathrm{kHz}$ (1:2 sample). For the HT phase of $\mathrm{LiBH}_{4}$, our value of $\nu_{\mathrm{Q}}$ is close to those found earlier. ${ }^{2,8,16}$ The value of $\nu_{\mathrm{Q}}$ $=31.6 \mathrm{kHz}$ reported for the $\mathrm{LiBH}_{4}-\mathrm{LiI}(3: 1)$ solid solution ${ }^{8}$ appears to be between our values for the HT phase of $\mathrm{LiBH}_{4}$ and the 2:1 sample. Addressing the changes in the Li jump rate for different $\mathrm{LiBH}_{4}-\mathrm{LiI}$ solid solutions, we can conclude that the shifts of both the position of the $R_{1}^{\mathrm{Li}}$ peak (Figure 6) and the "step" of the ${ }^{7} \mathrm{Li}$ NMR line width (Figure 7) suggest a decrease in $\tau_{\mathrm{d}}^{-1}$ with increasing iodine content. This is consistent with our proton spin-lattice relaxation results discussed above. It should be noted, however, that the ${ }^{7} \mathrm{Li}$ spin-lattice relaxation data reported for the $\mathrm{LiBH}_{4}-\mathrm{LiI}$ solid solutions with small iodine content $(7: 1 \text { and } 3: 1 \text { samples })^{8}$ suggested a certain increase in lithium ion mobility with respect to the HT phase of $\mathrm{LiBH}_{4}$. Thus, the dependence of $\tau_{\mathrm{d}}{ }^{-1}$ on the iodine concentration may be nonmonotonic.

Reorientational Motion of $\mathrm{BH}_{4}$ Groups. In this section, we shall discuss the parameters of $\mathrm{BH}_{4}$ reorientations which govern the behavior of the spin-lattice relaxation rates in the region of the low-temperature peak for $\mathrm{LiBH}_{4}-\mathrm{LiI}$ solid solutions. The dominant contribution to the ${ }^{1} \mathrm{H}$ spin-lattice relaxation rates in this region originates from the ${ }^{1} \mathrm{H}-{ }^{11} \mathrm{~B}$ and ${ }^{1} \mathrm{H}-{ }^{1} \mathrm{H}$ dipole-dipole interactions. ${ }^{15,18}$ As noted above, the frequency dependence of $R_{1}^{\mathrm{H}}$ in this region (see Figure 1) suggests a certain distribution of the reorientation jump rates $\tau^{-1}$. The presence of such a distribution in $\mathrm{LiBH}_{4}-\mathrm{LiI}$ solid solutions can be expected, since the local environment of a $\mathrm{BH}_{4}$ group changes from one group to another. For disordered solids, the simplest approach to the description of a jump rate distribution is based on the model with a Gaussian distribution of the activation energies. ${ }^{30}$ However, this simple model is not sufficient in our case. In fact, the frequency dependence of $R_{1}^{\mathrm{H}}$ persists up to temperatures well above the peak; furthermore, the relaxation rate data presented in Figure 1 exhibit a "shoulder" near $95 \mathrm{~K}$. These features suggest that the temperature dependence of $R_{1}^{\mathrm{H}}$ for the 2:1 sample can be described as a superposition of two partially overlapping peaks. Similar behavior of $R_{1}^{\mathrm{H}}(T)$ is also observed for the 1:1 and $1: 2$ samples, although for these samples the "shoulder" is less pronounced. Therefore, we assume a coexistence of two jump processes with different characteristic jump rates. We will use the subscript $i(i=1,2)$ to denote the two jump processes assuming that $i=1$ corresponds to the faster motion (i.e., the one giving rise to the $R_{1}^{\mathrm{H}}$ peak at lower $T$ ). For this model

$$
R_{1}^{\mathrm{H}}=R_{11}^{\mathrm{H}}+R_{12}^{\mathrm{H}}
$$

where $R_{1 i}^{\mathrm{H}}$ is expressed as ${ }^{30}$

$$
R_{1 i}^{\mathrm{H}}=\int R_{1 i}^{\mathrm{H}}\left(E_{\mathrm{a} i}\right) G\left(E_{\mathrm{a} i}, \bar{E}_{\mathrm{a} i}, \Delta E_{\mathrm{a} i}\right) \mathrm{d} E_{\mathrm{a} i}
$$

Here $G\left(E_{\mathrm{a} i}, \bar{E}_{\mathrm{ai}}, \Delta E_{\mathrm{ai}}\right)$ is a Gaussian distribution function centered at $\bar{E}_{\mathrm{a} i}$ with the dispersion $\Delta E_{\mathrm{a} i}$ and $R_{1 i}^{\mathrm{H}}\left(E_{\mathrm{ai}}\right)$ is given by the standard theory ${ }^{31}$

$$
\begin{aligned}
& R_{1 i}^{\mathrm{H}}\left(E_{\mathrm{a} i}\right)=\frac{\Delta M_{\mathrm{HB} i} \tau_{i}}{2}\left[\frac{1}{1+\left(\omega_{\mathrm{H}}-\omega_{\mathrm{B}}\right)^{2} \tau_{i}^{2}}+\frac{3}{1+\omega_{\mathrm{H}}{ }^{2} \tau_{i}^{2}}\right. \\
& \left.+\frac{6}{1+\left(\omega_{\mathrm{H}}+\omega_{\mathrm{B}}\right)^{2} \tau_{i}^{2}}\right]+\frac{4 \Delta M_{\mathrm{HH} i} \tau_{i}}{3}\left[\frac{1}{4+\omega_{\mathrm{H}}{ }^{2} \tau_{i}^{2}}\right. \\
& \left.+\frac{1}{1+\omega_{\mathrm{H}}{ }^{2} \tau_{i}^{2}}\right]
\end{aligned}
$$

where the equation analogous to eq 1 relates the jump rates $\tau_{i}^{-1}$ and the corresponding activation energies $E_{a i}, \omega_{\mathrm{H}}$ and $\omega_{\mathrm{B}}$ are the resonance frequencies of ${ }^{1} \mathrm{H}$ and ${ }^{11} \mathrm{~B}$, respectively, and $\Delta M_{\mathrm{HBi}}$ and $\Delta M_{\mathrm{HH} i}$ are the parts of the dipolar second moment due to ${ }^{1} \mathrm{H}-{ }^{11} \mathrm{~B}$ and ${ }^{1} \mathrm{H}-{ }^{1} \mathrm{H}$ interactions that are caused to fluctuate by the $i$ th type of reorientational motion. The parameters of the model are $\Delta M_{\mathrm{HB} i}, \Delta M_{\mathrm{HH} i}, \tau_{0 i}, \bar{E}_{\mathrm{a} i}$ and $\Delta E_{\mathrm{a} i}$. These parameters can be varied to find the best fit to the $R_{1}^{\mathrm{H}}(T)$ data at the three resonance frequencies simultaneously. Since the $\mathrm{H}-\mathrm{B}$ and $\mathrm{H}-\mathrm{H}$ terms in eq 4 show nearly the same temperature and frequency dependences, it is practically impossible to determine the amplitude parameters $\Delta M_{\mathrm{HB} i}$ and $\Delta M_{\mathrm{HH} i}$ independently from the fits. The estimates for alkali-metal borohydrides ${ }^{15,18}$ indicate that $\Delta M_{\mathrm{HB} i}$ and $\Delta M_{\mathrm{HH} i}$ are close to each other. Therefore, for parametrization of the $R_{1}^{\mathrm{H}}$ data we shall assume that $\Delta M_{\mathrm{HB} i}=\Delta M_{\mathrm{HH} i} \equiv \Delta M_{i}$. The results of the simultaneous fit of the two-peak model (eqs 2-4 and the analogue of eq 1) to the data for the 2:1 sample are shown by solid curves in Figure 1. It can be seen that this model satisfactorily describes the experimental data over wide ranges of temperature and resonance frequency. The values of the amplitude parameters resulting from this fit are $\Delta M_{1}=1.2 \times$ $10^{10} \mathrm{~s}^{-2}$ and $\Delta M_{2}=1.2 \times 10^{9} \mathrm{~s}^{-2}$, and the corresponding 
motional parameters are $\tau_{01}=(4.1 \pm 0.4) \times 10^{-14} \mathrm{~s}, \bar{E}_{\mathrm{a} 1}=53 \pm$ $4 \mathrm{meV}, \Delta E_{\mathrm{a} 1}=19 \pm 3 \mathrm{meV}$, and $\tau_{02}=(3.9 \pm 0.6) \times 10^{-14} \mathrm{~s}, \bar{E}_{\mathrm{a} 2}$ $=104 \pm 7 \mathrm{meV}$, and $\Delta E_{\mathrm{a} 2}=14 \pm 5 \mathrm{meV}$. It should be noted that the value of the average activation energy for the main peak, $\bar{E}_{\mathrm{a}}$, resulting from this fit is close to the activation energy (46 meV) derived from QENS experiments ${ }^{29}$ for the 2:1 sample. A similar approach based on the simultaneous fit of the two-peak model to the data has been used for the $1: 1$ and 1:2 samples. The results of these fits at $\omega / 2 \pi=23.8 \mathrm{MHz}$ are shown by solid lines in Figure 2. For the 1:1 sample, the values of the corresponding amplitude parameters are $\Delta M_{1}=1.3 \times$ $10^{10} \mathrm{~s}^{-2}$ and $\Delta M_{2}=1.4 \times 10^{9} \mathrm{~s}^{-2}$, and the motional parameters are $\tau_{01}=(4.1 \pm 0.6) \times 10^{-14} \mathrm{~s}, \bar{E}_{\mathrm{a} 1}=39 \pm 4 \mathrm{meV}, \Delta E_{\mathrm{a} 1}=11 \pm$ $3 \mathrm{meV}$, and $\tau_{02}=(6.9 \pm 0.8) \times 10^{-14} \mathrm{~s}, \bar{E}_{\mathrm{a} 2}=57 \pm 8 \mathrm{meV}, \Delta E_{\mathrm{a} 2}$ $=13 \pm 5 \mathrm{meV}$. Again, the average activation energy for the main peak, $\bar{E}_{\mathrm{a} 1}$, appears to be close to the activation energy ( 38 $\mathrm{meV}$ ) derived from QENS experiments ${ }^{29}$ for the 1:1 sample. For the 1:2 sample, the amplitude parameters are $\Delta M_{1}=1.4 \times$ $10^{10} \mathrm{~s}^{-2}$ and $\Delta M_{2}=1.4 \times 10^{9} \mathrm{~s}^{-2}$, and the motional parameters are $\tau_{01}=(4.1 \pm 0.7) \times 10^{-14} \mathrm{~s}, \bar{E}_{\mathrm{a} 1}=33 \pm 4 \mathrm{meV}, \Delta E_{\mathrm{a} 1}=11 \pm$ $3 \mathrm{meV}$, and $\tau_{02}=(5.9 \pm 0.9) \times 10^{-14} \mathrm{~s}, \bar{E}_{\mathrm{a} 2}=49 \pm 7 \mathrm{meV}, \Delta E_{\mathrm{a} 2}$ $=13 \pm 5 \mathrm{meV}$.

It should be noted that the presence of two frequency scales of the reorientational motion in $\mathrm{LiBH}_{4}-\mathrm{LiI}$ solid solutions has not been revealed by QENS experiments. ${ }^{29}$ This may be related to the limited temperature and dynamic ranges of the QENS measurements. In fact, the range of changes in $\tau^{-1}$ observed in QENS experiments ${ }^{29}$ is less than 1 order of magnitude. Comparison with our NMR results indicates that the QENS data $^{29}$ are dominated by the faster reorientational process. It is interesting to compare the resulting $\mathrm{H}$ jump rates at a certain temperature. We have chosen $200 \mathrm{~K}$ as a temperature for such a comparison, since this is the lowest temperature at which the QENS data for $\mathrm{LiBH}_{4}-\mathrm{LiI}$ solid solutions ${ }^{29}$ are available. For the $2: 1$ sample, the most probable values of $\tau_{1}^{-1}(200 \mathrm{~K})$ and $\tau_{2}{ }^{-1}(200 \mathrm{~K})$ resulting from our fits are $1.2 \times 10^{12} \mathrm{~s}^{-1}$ and $6.0 \times$ $10^{10} \mathrm{~s}^{-1}$, respectively. The value of $\tau^{-1}(200 \mathrm{~K})$ obtained from QENS experiments ${ }^{29}$ for the $2: 1$ sample $\left(\sim 8.3 \times 10^{11} \mathrm{~s}^{-1}\right)$ lies between these two values, being close to $\tau_{1}^{-1}(200 \mathrm{~K})$. For the $1: 1$ sample, the most probable values of $\tau_{1}^{-1}(200 \mathrm{~K})$ and $\tau_{2}{ }^{-1}(200 \mathrm{~K})$ resulting from our fits are $2.6 \times 10^{12} \mathrm{~s}^{-1}$ and $5.3 \times$ $10^{11} \mathrm{~s}^{-1}$, respectively. Again, the value of $\tau^{-1}(200 \mathrm{~K})$ derived from QENS experiments ${ }^{29}$ for the $1: 1$ sample $\left(\sim 9.5 \times 10^{11} \mathrm{~s}^{-1}\right)$ lies between these two values. For the 2:1 sample, there are no reported QENS data, and the most probable values of $\tau_{1}{ }^{-1}(200$ $\mathrm{K})$ and $\tau_{2}^{-1}(200 \mathrm{~K})$ resulting from our fits are $3.7 \times 10^{12} \mathrm{~s}^{-1}$ and $9.8 \times 10^{11} \mathrm{~s}^{-1}$, respectively.

The local environment of the $\mathrm{BH}_{4}$ group in the hexagonal $\mathrm{LiBH}_{4}$ is shown in Figure 9. The c-axis is oriented vertically. The results of the recent QENS study of the nature of $\mathrm{BH}_{4}$ reorientations in the HT phase of $\mathrm{LiBH}_{4}$ (ref 7) suggest a reorientational mechanism described by the rotation around the 3 -fold axis parallel to the hexagonal $c$-axis, combined with jump exchanges between the rotating $\mathrm{H}$ atoms and the remaining axial $\mathrm{H}$ atom via appropriate 2 -fold and/or 3-fold reorientations. On the basis of these results, we can attribute the faster jump process revealed by proton NMR in $\mathrm{LiBH}_{4}-\mathrm{LiI}$ solid solutions to the rotation around the principal 3-fold axis, while the slower jump process can be ascribed to jump exchanges with the axial $\mathrm{H}$ atom. The local structural arrangement shown in Figure 9 appears to be favorable for the rotation around the principal 3-fold axis. This is supported by the results of DFT calculations of the potential energy landscapes, ${ }^{32}$ which show

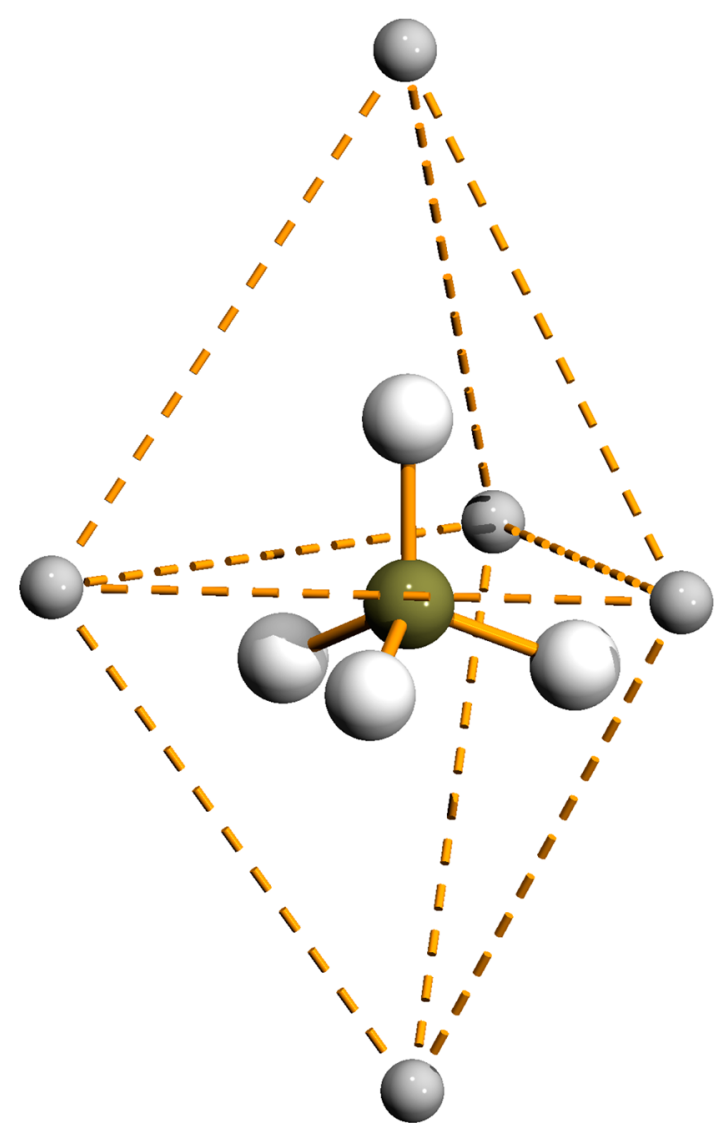

Figure 9. $\mathrm{Li}$ atom environment of the $\mathrm{BH}_{4}$ group in the hexagonal $\mathrm{LiBH}_{4}$. The $c$-axis is oriented vertically. The appropriate interatomic distances are listed in Table S2 of the Supporting Information.

that the energy barriers for $\mathrm{BH}_{4}$ rotations around the 3-fold axis in the hexagonal phase of $\mathrm{LiBH}_{4}$ are considerably lower than the barriers for all possible $\mathrm{BH}_{4}$ rotations in the orthorhombic phase of $\mathrm{LiBH}_{4}$. The observed decrease in the average activation energies with increasing iodine content in $\mathrm{LiBH}_{4}-$ LiI solid solutions can be qualitatively explained by the increase in the lattice parameters (see Table S1 of the Supporting Information). In fact, since the ionic radius of $\mathrm{I}^{-}$is larger than that of $\mathrm{BH}_{4}^{-}$, the increasing iodine content results in increasing distances between $\mathrm{H}$ atoms and the nearest-neighbor $\mathrm{Li}$ atoms; this is expected to lead to weaker $\mathrm{H}-\mathrm{Li}$ interactions and to lower barriers for reorientations.

Lithium Diffusion. In this section, we shall discuss the parameters of the translational $\mathrm{Li}$ diffusion that governs the behavior of the spin-lattice relaxation rates in the region of the high-temperature peak for $\mathrm{LiBH}_{4}-\mathrm{LiI}$ solid solutions. It should be noted that in the region between the low-temperature and high-temperature $R_{1}^{\mathrm{H}}(T)$ peaks, an additional frequencydependent contribution to the relaxation rate becomes evident. This is reflected in the fact that the minimum $R_{1}^{\mathrm{H}}(T)$ value at 14 $\mathrm{MHz}$ is nearly an order of magnitude higher than the corresponding value at $23.8 \mathrm{MHz}$ (see Figures 1 and 3). Because of the presence of such a contribution not related to the motionally modulated dipole-dipole interaction, it is not possible to model the $R_{1}^{\mathrm{H}}(T)$ data in our systems just as a sum of two peaks due to $\mathrm{BH}_{4}$ reorientations and $\mathrm{Li}$ diffusion over the entire temperature range studied, especially at low resonance frequencies. The additional relaxation mechanism may originate from the interaction between nuclear spins and 
paramagnetic centers. ${ }^{33}$ In fact, ball milling can lead to an appearance of paramagnetic centers, both extrinsic and intrinsic (dangling bonds). ${ }^{34}$ The presence of the additional relaxation contribution limits the temperature ranges over which the $R_{1}^{\mathrm{H}}(T)$ data can be described in terms of the motionally modulated dipole-dipole interaction. Near the high-temperature $R_{1}^{\mathrm{H}}(T)$ peak, Li ions are the only species moving with the jump rates $\tau_{\mathrm{d}}{ }^{-1}$ that are close enough to the resonance frequency, and the behavior of the proton spin-lattice relaxation rate should be dominated by the ${ }^{1} \mathrm{H}-{ }^{7} \mathrm{Li}$ dipoledipole interaction. The simplest description is given by the Bloembergen-Purcell-Pound (BPP) model $^{35}$

$$
\begin{aligned}
R_{1}^{\mathrm{H}} & =\frac{\Delta M_{\mathrm{HLi}} \tau_{\mathrm{d}}}{2}\left[\frac{1}{1+\left(\omega_{\mathrm{H}}-\omega_{\mathrm{Li}}\right)^{2} \tau_{\mathrm{d}}{ }^{2}}+\frac{3}{1+\omega_{\mathrm{H}}{ }^{2} \tau_{\mathrm{d}}{ }^{2}}\right. \\
& \left.+\frac{6}{1+\left(\omega_{\mathrm{H}}+\omega_{\mathrm{Li}}\right)^{2} \tau_{\mathrm{d}}{ }^{2}}\right]
\end{aligned}
$$

and the Arrhenius relation for $\tau_{\mathrm{d}}^{-1}$

$$
\tau_{\mathrm{d}}^{-1}=\tau_{\mathrm{d} 0}^{-1} \exp \left(-E_{\mathrm{a}}^{\mathrm{d}} / k_{\mathrm{B}} T\right)
$$

where $\omega_{\mathrm{Li}}$ is the resonance frequency of ${ }^{7} \mathrm{Li}, E_{\mathrm{a}}^{\mathrm{d}}$ is the activation energy for $\mathrm{Li}$ diffusion, and $\Delta M_{\mathrm{HLi}}$ is the part of the second moment due to ${ }^{1} \mathrm{H}-{ }^{7} \mathrm{Li}$ dipole-dipole interaction that is caused to fluctuate by $\mathrm{Li}$ jump diffusion. We have found that eqs 5 and 6 provide a satisfactory description of the $R_{1}^{\mathrm{H}}(T)$ data near the high-temperature peak for different resonance frequencies; in this case, it is not necessary to introduce any distributions of $\tau_{\mathrm{d}}{ }^{-1}$ values. The simultaneous fits of eqs 5 and 6 to the data result in the following parameters: for the 2:1 sample, $\Delta M_{\mathrm{HLi}}=5.0 \times 10^{8} \mathrm{~s}^{-2}, \tau_{\mathrm{d} 0}=3.1 \times 10^{-16} \mathrm{~s}, E_{\mathrm{a}}^{\mathrm{d}}=0.63$ $\mathrm{eV}$, for the 1:1 sample, $\Delta M_{\mathrm{HLi}}=5.0 \times 10^{8} \mathrm{~s}^{-2}, \tau_{\mathrm{d} 0}=7.1 \times 10^{-16}$ s, $E_{\mathrm{a}}^{\mathrm{d}}=0.65 \mathrm{eV}$, and for the $1: 2$ sample, $\Delta M_{\mathrm{HLi}}=5.4 \times 10^{8} \mathrm{~s}^{-2}$, $\tau_{\mathrm{d} 0}=7.1 \times 10^{-16} \mathrm{~s}, E_{\mathrm{a}}^{\mathrm{d}}=0.68 \mathrm{eV}$. The results of these simultaneous fits are shown by the solid lines in Figures 3 and 4. For the $\mathrm{HT}$ phase of $\mathrm{LiBH}_{4}$, the reported values of the activation energy for Li diffusion are $0.56 \mathrm{eV}^{2,17}$ and $0.54 \mathrm{eV}^{20}$ Thus, the activation energy for $\mathrm{Li}$ diffusion increases with increasing iodine content. The estimates of the $\mathrm{Li}$ jump rates at $500 \mathrm{~K}, \tau_{\mathrm{d}}^{-1}(500 \mathrm{~K})$, based on our fits and the Arrhenius relation (eq 6), are $1.4 \times 10^{9} \mathrm{~s}^{-1}$ (for the $2: 1$ sample), $4.0 \times 10^{8}$ $\mathrm{s}^{-1}$ (for the 1:1 sample), and $2.0 \times 10^{8} \mathrm{~s}^{-1}$ (for the 1:2 sample). These values should be compared to the value $\tau_{\mathrm{d}}^{-1}(500 \mathrm{~K})=$ $2.1 \times 10^{9} \mathrm{~s}^{-1}$ derived for the HT phase of $\mathrm{LiBH}_{4} \cdot{ }^{17}$

As noted above, at small iodine concentrations, the $\mathrm{Li}$ jump rate has been found to increase with increasing $\mathrm{I}^{-}$content. $^{8}$ Thus, the dependence of $\tau_{\mathrm{d}}^{-1}$ on the iodine concentration in $\mathrm{Li}\left(\mathrm{BH}_{4}\right)_{1-y} \mathrm{I}_{y}$ should be nonmonotonic. This is consistent with the behavior of the activation energy for $\mathrm{Li}$ ion conductivity showing a minimum near $y=0.125 .{ }^{12}$ The nonmonotonic dependence of the Li jump rate on the iodine content may result from a competition of two factors: the weakening of the $\mathrm{Li}$... $\mathrm{H}$ bonds and the increase in the distances between the $\mathrm{Li}$ sites. In fact, the increase in the iodine content in $\mathrm{LiBH}_{4}-\mathrm{LiI}$ solid solutions leads to the increase in the lattice parameters (see Table S1 of the Supporting Information). This is expected to weaken the $\mathrm{Li}$... H interaction and to facilitate $\mathrm{Li}$ jumps. On the other hand, the increase in the distances between the $\mathrm{Li}$ sites is expected to reduce the probability of $\mathrm{Li}$ jumps. This factor is likely to dominate at high iodine concentrations. Indeed, the nearest-neighbor $\mathrm{Li}-\mathrm{Li}$ distances in the $a b$ plane change from $4.240 \AA$ for the HT phase of $\mathrm{LiBH}_{4}$ to $4.428 \AA$ for the $\mathrm{LiBH}_{4}-\mathrm{LiI}(1: 2)$ sample. It should be noted that the analysis of the frequency dependences of the ${ }^{7} \mathrm{Li}$ and ${ }^{6} \mathrm{Li}$ spinlattice relaxation rates in the $\mathrm{HT}$ phase of $\mathrm{LiBH}_{4}$ performed by Epp and Wilkening ${ }^{20}$ suggests the quasi-two-dimensional nature of $\mathrm{Li}$ diffusion in this compound. A discussion of possible effects of reduced dimensionality on $\mathrm{Li}$ motion in $\mathrm{LiBH}_{4}-\mathrm{LiI}$ solid solutions is beyond the scope of the present paper. As the concluding remark, we would like to note that the hexagonal structure of the $\mathrm{HT}$ phase of $\mathrm{LiBH}_{4}$ appears to be favorable for both the fast reorientational motion of $\mathrm{BH}_{4}$ groups and the fast $\mathrm{Li}$ diffusion. A search for a possible relation between these two types of motion could be a promising direction for future investigations.

\section{CONCLUSIONS}

The analysis of the measured ${ }^{1} \mathrm{H},{ }^{11} \mathrm{~B}$, and ${ }^{7} \mathrm{Li}$ spin-lattice relaxation rates for hexagonal $\mathrm{LiBH}_{4}-\mathrm{LiI}$ solid solutions with $2: 1,1: 1$, and 1:2 molar ratios has revealed the parameters of $\mathrm{BH}_{4}$ reorientations and $\mathrm{Li}$ diffusion in these compounds. Our results show that, at low temperatures, the reorientational motion of $\mathrm{BH}_{4}$ groups in $\mathrm{LiBH}_{4}-\mathrm{LiI}$ solid solutions is much faster than in all other borohydride-based systems studied so far. The low-temperature rates of $\mathrm{BH}_{4}$ reorientations increase with increasing iodine content. For the $\mathrm{LiBH}_{4}-\mathrm{LiI}$ samples with $2: 1,1: 1$, and 1:2 molar ratios, the most probable values of the reorientational jump rate are found to reach $\sim 10^{8} \mathrm{~s}^{-1}$ at 55 , 40 , and $33 \mathrm{~K}$, respectively. However, the reorientational motion in $\mathrm{LiBH}_{4}-\mathrm{LiI}$ solid solutions cannot be described in terms of a single activation energy. Our results are consistent with a coexistence of at least two types of reorientational processes with different characteristic rates, and each of these processes can be described by a certain distribution of the activation energies. For the faster reorientational process, the average activation energies derived from our data are $53 \pm 4,39 \pm 4$, and $33 \pm 4 \mathrm{meV}$ for the samples with 2:1, 1:1, and 1:2 molar ratios, respectively. For the slower process, the corresponding average activation energies are $104 \pm 7 \mathrm{meV}(2: 1), 57 \pm 8 \mathrm{meV}$ (1:1), and $49 \pm 7 \mathrm{meV}(1: 2)$.

Above $350 \mathrm{~K}, \mathrm{BH}_{4}$ reorientations in $\mathrm{LiBH}_{4}-\mathrm{LiI}$ solid solutions become too fast to be probed by NMR, and the measured spin-lattice relaxation rates in this range are governed by the translational diffusion of $\mathrm{Li}$ ions. For the studied $\mathrm{LiBH}_{4}-\mathrm{LiI}$ samples with 2:1, 1:1, and 1:2 molar ratios, the $\mathrm{Li}$ jump rates are found to decrease with increasing iodine content. The activation energies for $\mathrm{Li}$ diffusion derived from our data are $0.63,0.65$, and $0.68 \mathrm{eV}$ for the samples with $2: 1$, $1: 1$, and $1: 2$ molar ratios, respectively.

\section{ASSOCIATED CONTENT}

\section{S Supporting Information}

Results of the structural analysis and FT-IR spectra of the studied samples. This material is available free of charge via the Internet at http://pubs.acs.org.

\section{AUTHOR INFORMATION}

\section{Corresponding Author}

*E-mail skripov@imp.uran.ru; Fax +7-343-374-5244.

\section{Notes}

The authors declare no competing financial interest. 


\section{ACKNOWLEDGMENTS}

This work was partially supported by the Russian Foundation for Basic Research (Grant No. 12-03-00078) and by the Priority Program "Physico-technical principles of development of technologies and devices for smart adaptive electrical networks" of the Russian Academy of Sciences. The authors also acknowledge funding from the European Community's Seventh Framework Program FP7/2007-2013 under Grant Agreement No. 226943-FLYHY, the Danish National Research Foundation (Center for Materials Crystallography), the Danish Strategic Research Council (Center for Energy Materials and the HyFillFast project), and the Carlsberg Foundation.

\section{REFERENCES}

(1) Orimo, S.; Nakamori, Y.; Elisen, J. R.; Züttel, A.; Jensen, C. M. Chem. Rev. 2007, 107, 4111-4132.

(2) Matsuo, M.; Nakamori, Y.; Orimo, S.; Maekawa, H.; Takamura, H. Appl. Phys. Lett. 2007, 91, 224103.

(3) Soulié, J.-P.; Renaudin, G.; Černý, R.; Yvon, K. J. Alloys Compd. 2002, 346, 200-205.

(4) Hartman, M. R.; Rush, J. J.; Udovic, T. J.; Bowman, R. C.; Hwang, S.-J. J. Solid State Chem. 2007, 180, 1298-1305.

(5) Filinchuk, Y.; Chernyshov, D.; Černý, R. J. Phys. Chem. C 2008, 112, 10579-10584.

(6) Remhof, A.; Łodziana, Z.; Martelli, P.; Friedrichs, O.; Züttel, A.; Skripov, A. V.; Embs, J. P.; Strässle, T. Phys. Rev. B 2010, 81, 214304.

(7) Verdal, N.; Udovic, T. J.; Rush, J. J. J. Phys. Chem. C 2012, 116, 1614-1618.

(8) Maekawa, H.; Matsuo, M.; Takamura, H.; Ando, M.; Noda, Y.; Karahashi, T.; Orimo, S. J. Am. Chem. Soc. 2009, 131, 894-895.

(9) Matsuo, M.; Takamura, H.; Maekawa, H.; Li, H.-W.; Orimo, S. Appl. Phys. Lett. 2009, 94, 084103.

(10) Arnbjerg, L. M.; Ravnsbæk, D. B.; Filinchuk, Y.; Vang, R. T.; Cerenius, Y.; Besenbacher, F.; Jørgensen, J.-E.; Jakobsen, H. J.; Jensen, T. R. Chem. Mater. 2009, 21, 5772-5782.

(11) Rude, L. H.; Groppo, E.; Arnbjerg, L. M.; Ravnsbæk, D. B.; Malmkjær, R. A.; Filinchuk, Y.; Baricco, M.; Besenbacher, F.; Jensen, T. R. J. Alloys Compd. 2011, 509, 8299-8305.

(12) Miyazaki, R.; Karahashi, T.; Kumatani, N.; Noda, Y.; Ando, M.; Takamura, H.; Matsuo, M.; Orimo, S.; Maekawa, H. Solid State Ionics 2011, 192, 143-147.

(13) Tsang, T.; Farrar, T. C. J. Chem. Phys. 1969, 50, 3498-3502.

(14) Tarasov, V. P.; Bakum, S. I.; Privalov, V. I.; Shamov, A. A. Russ. J. Inorg. Chem. 1990, 35, 1035-1039.

(15) Skripov, A. V.; Soloninin, A. V.; Filinchuk, Y.; Chernyshov, D. J. Phys. Chem. C 2008, 112, 18701-18705.

(16) Corey, R. L.; Shane, D. T.; Bowman, R. C.; Conradi, M. S. J. Phys. Chem. C 2008, 112, 18706-18710.

(17) Soloninin, A. V.; Skripov, A. V.; Buzlukov, A. L.; Stepanov, A. P. J. Solid State Chem. 2009, 182, 2357-2361.

(18) Babanova, O. A.; Soloninin, A. V.; Stepanov, A. P.; Skripov, A. V.; Filinchuk, Y. J. Phys. Chem. C 2010, 114, 3712-3718.

(19) Skripov, A. V.; Soloninin, A. V.; Babanova, O. A.; Hagemann, H.; Filinchuk, Y. J. Phys. Chem. C 2010, 114, 12370-12374.

(20) Epp, V.; Wilkening, M. Phys. Rev. B 2010, 82, 020301(R).

(21) Shane, D. T.; Rayhel, L. H.; Huang, Z.; Zhao, J. C.; Tang, X.; Stavila, V.; Conradi, M. S. J. Phys. Chem. C 2011, 115, 3172-3177.

(22) Babanova, O. A.; Soloninin, A. V.; Skripov, A. V.; Ravnsbæk, D. B.; Jensen, T. R.; Filinchuk, Y. J. Phys. Chem. C 2011, 115, 1030510309.

(23) Jimura, K.; Hayashi, S. J. Phys. Chem. C 2012, 116, 4883-4891.

(24) Soloninin, A. V.; Babanova, O. A.; Skripov, A. V.; Hagemann, H.; Richter, B.; Jensen, T. R.; Filinchuk, Y. J. Phys. Chem. C 2012, 116, 4913-4920.

(25) Remhof, A.; Łodziana, Z.; Buchter, F.; Martelli, P.; Pendolino, F.; Friedrichs, O.; Züttel, A.; Embs, J. P. J. Phys. Chem. C 2009, 113, 16834-16837.
(26) Verdal, N.; Hartman, M. R.; Jenkins, T.; DeVries, D. J.; Rush, J. J.; Udovic, T. J. J. Phys. Chem. C 2010, 114, 10027-10033.

(27) Blanchard, D.; Riktor, M. D.; Maronsson, J. B.; Jacobsen, H. S.; Kehres, J.; Sveinbjörnsson, D.; Bardaji, E. G.; Léon, A.; Juranyi, F.; Wuttke, J.; et al. J. Phys. Chem. C 2010, 114, 20249-20257.

(28) Blanchard, D.; Maronsson, J. B.; Riktor, M. D.; Kheres, J.; Sveinbjörnsson, D.; Bardaji, E. G.; Léon, A.; Juranyi, F.; Wuttke, J.; Lefmann, K.; et al. J. Phys. Chem. C 2012, 116, 2013-2023.

(29) Martelli, P.; Remhof, A.; Borgschulte, A.; Ackermann, R.; Strässle, T.; Embs, J. P.; Ernst, M.; Matsuo, M.; Orimo, S.; Züttel, A. J. Phys. Chem. A 2011, 115, 5329-5334.

(30) Markert, J. T.; Cotts, E. J.; Cotts, R. M. Phys. Rev. B 1988, 37, 6446-6452.

(31) Abragam, A. The Principles of Nuclear Magnetism; Clarendon Press: Oxford, 1961.

(32) Buchter, F.; Łodziana, Z.; Mauron, P.; Remhof, A.; Friedrichs, O.; Borgschulte, A.; Züttel, A.; Sheptyakov, D.; Strässle, T.; RamirezCuesta, A. J. Phys. Rev. B 2008, 78, 094302.

(33) Phua, T. T.; Beaudry, B. J.; Peterson, D. T.; Torgeson, D. R.; Barnes, R. G.; Belhoul, M.; Styles, G. A.; Seymour, E. F. W. Phys. Rev. B 1983, 28, 6227-6250.

(34) Skripov, A. V.; Soloninin, A. V.; Buzlukov, A. L.; Tankeyev, A. P.; Yermakov, A.Ye.; Mushnikov, N. V.; Uimin, M. A.; Gaviko, V. S. J. Alloys Compd. 2007, 446-447, 489-494.

(35) Bloembergen, N.; Purcell, E. M.; Pound, R. M. Phys. Rev. 1948, $73,679-712$. 